\title{
Comparison of Actual with Estimated Weight and Height in Children with Sickle Cell Anaemia in Lagos, Nigeria
}

Akodu SO*, Adekanmbi AF, Ogunlesi TA.

Department of Paediatrics, Olabisi Onabanjo University Teaching Hospital, Sagamu, Ogun, Nigeria

*Corresponding Author: Akodu Samuel Olufemi. Department of Paediatrics, Olabisi Onabanjo University Teaching Hospital, Sagamu, Ogun, Nigeria.

\begin{abstract}
Sickle cell disorders are the most common genetic disorders worldwide as well as in Nigeria. The weight and height are the most used anthropometric measurements in paediatric practice for the calculation of many parameters. The objective is to determine the reliability of weight and height estimates among children with sickle cell anaemia compared with measured weight and height. A random sample of SCA children aged eight months to 12 years was studied. Height and weight were measured using standard methods, while BMI was estimated using $\mathrm{kg} / \mathrm{m} 2$. These were compared with estimated weight, height and BMI. Five subjects were adjudged obese using estimated BMI: three of these five subjects were identified as obese using actual BMI. Regression analysis showed that there appears to be more positive linear relationship for weight and length/height among children aged 1- 6 years. The measured mean weight and BMI were significantly lower than the estimated mean values. The overall mean of estimated length/height did not differ significantly from overall mean of the actual length/height. In comparison with the actual BMI, the estimated BMI did not identify any of the subjects with either thinness or overweight while children with obesity were over-estimated. The formula methods of estimating weights and heights for the various ages in children with sickle cell anaemia are over-estimating their actual values; this is more obvious for weight.
\end{abstract}

Keywords: Measured, Estimated,Weight, Height, Body mass index

\section{INTRODUCTION}

$\mathrm{S}_{\mathrm{s}}^{\mathrm{i}}$ ickle cell anaemia is one of the commonest single gene disorders in man with variable distribution in different parts of the world and variable clinical manifestations. ${ }^{1}$ In Nigeria, the prevalence of sickle cell trait is about $25 \%$ while the homozygous state is found in about $3 \%$ of the population ${ }^{2}$. Africa has $70 \%$ of the world's annual figure of 300,000 affected new births. ${ }^{3}$ Nigeria has the highest burden worldwide. ${ }^{4} \mathrm{~A}$ recent WHO report estimated that approximately 20 per 1,000 births in Nigeria are affected by sickle cell anemia, giving a total of about 150,000 affected children born every year in Nigeria alone. ${ }^{5}$ The periodic measurement of height and weight are important parts of routine healthcare for all children, including those with sickle cell anaemia, and comparison of these measurements against reference standards or norms can serve as a screening tool for nutritional problems. Sickle cell anaemia commonly affects growth, leading to low mean weight, low mean height and decreased height velocity. ${ }^{6-10}$ However, there are difficulties in obtaining accurate measurements of height in children with sickle cell anaemia that have 
incapacitating conditions because the pain of vaso-occlusive crisis in patients with sickle cell disease is excruciating, and incapacitating to enable height measurement. Therefore under these difficult circumstances the weight and height have to be estimated. Children with sickle cell anaemia are vulnerable to growth deficits, of which stunting in height is one of those commonly described. ${ }^{6-10}$ The weight and height for age estimated using the universally accepted formulae uses a specific set of equations validated on the general population without sickle cell anaemia. Although the technique and these equations are widely used, to date no study has been published which established that it's equally useful among children with sickle cell anaemia.

This study was carried out to determine whether estimated weight and height among children with sickle cell anaemia agrees with measured weight and height. In addition we investigated whether Body Mass Index (BMI) calculated on the basis of estimated weight and height values agree with BMI values calculated on the basis of measured weight and height. It was a cross-sectional and descriptive study.

\section{MATERIALSAND METHODS}

The study subjects were children aged eight months to 12 years with sickle cell anaemia attending the sickle cell disease clinic of the Department of Paediatrics of Lagos State University Teaching Hospital, Ikeja, Lagos in South west Nigeria based on the clinic attendance records. The included children were in a steady state i.e. absence of any crisis in the preceding four weeks, no recent drop in the haemoglobin level and absence of any symptoms or sign attributable to an acute illness.11 They were also not taking medications known to affect growth e.g. steroids. All children, or parents when it concerned young children, gave informed consent for inclusion in the study.

Study subjects were recruited consecutively until the desired sample size was attained. This lasted three months. The study was performed according to the guidelines of the Medical Ethics Committee of the Lagos State University Teaching Hospital. The sample size was calculated with $90 \%$ power and $5 \%$ significance level (two-tailed) for prevalence of stunting of $25 \%$ reported by Henderson et al12 among children with sickle cell disease. In order to accommodate possible attrition or unforeseen errors in completing the study questionnaire, an additional 20\% (14 subjects) of the calculated figure was recruited to bring the figure to 86 , which was approximated to 90 subjects.

Subjects' weights were measured barefooted and wearing light clothing. Weight measurements were taken on a Seca 761 series mechanical floor scale to the nearest $0.1 \mathrm{Kg}$. Children two years of age and older had their heights measured using a stadiometer while the length of those below two years were measured using an infantometer. The various linear measurements were taken three times. Variation among measurements was not more than $0.3 \mathrm{~cm}$. The mean of these three measurements was recorded. For the purpose of quality assurance standardization of the instruments were done after every 10 measurements.

The weight and height for age were also estimated using the universally accepted formulae. The weight of the study subjects were estimated using the following formula ${ }^{13}$

For children aged less than one year: $(n+9) / 2$, where "n" is age in months.

For children aged $1-6$ years: $(2 n+8)$, where " $n$ " is age in years

For children aged $7-12$ years: $(7 n-5) / 2$, where " $n$ " is age in years

For the height estimate, the formula $(6 n+77)$, where " $n$ " is age in years, as recommended for children aged $2-12$ years was applied. The estimated height for children aged one year was taken as $75 \mathrm{~cm} .13$ The body mass index was calculated using the formula Weight in $\mathrm{kg} /$ Height in $\mathrm{m} 2(\mathrm{Kg} / \mathrm{m} 2) 14 \mathrm{Z}$ scores were generated for actual BMI as well as the estimated BMI.

The data were entered into a standard computer system. The data was analysed using Statistical Package for Social Science (SPSS) version 19.0. Scatter diagram was plotted to determine the relationship between actual and estimated parameters. The mean, standard deviation and other parameters of statistical location were generated as necessary. Tests of statistical significance between means of actual and estimated parameters were by paired Student $\mathrm{t}-$ test. Level of significance was set at $p<0.05$.

\section{Operational definition}

Actual weight - weight of patient measured with Seca by researcher

Actual height - height of patient measured with infantometer or stadiometer by researcher

Actual BMI - BMI of patient calculated on the basis of actual weight and height

Estimated weight - weight of patient estimated by 
researcher

Estimated height - height of patient estimated by researcher Estimated BMI - BMI of patient calculated on the basis of estimated weight and height

\section{RESULTS}

\section{Characteristics of the study population}

A total of 90 children who met the study criteria, were recruited over a study period of three months. The age and gender distribution of the study patients are given in Table I. Overall, the age of the subjects ranged from nine months to 12 years, with a mean of $67.73( \pm 43.78)$ months. The modal age group was $1-6$ years. The male to female ratio was $1: 1$.

\section{Comparison of mean actual and estimated parameters of study subjects}

This phase of analysis compared the measured parameters with the estimated parameters - Table II. The measured mean weight and BMI were significantly lower than the estimated mean of values. The overall mean of estimated length/height did not differ significantly from overall mean of the actual length/height. Further analysis of comparison between actual and estimated parameters shows that the least mean difference between estimated parameters and actual parameters was observed with length/height $(0.6 \pm 9.5 \mathrm{~cm})$ and highest with weight $(2.9 \pm 5.0 \mathrm{Kg})$.

\section{Scatter plot of actual and estimated parameters}

The scatter diagrams showing the relationship between actual and estimated parameters are shown in figures 1, 2, and 3 for weight, length/height, and BMI respectively. The plots showed linear relationship between actual and estimated parameters. However, there appears to be more positive linear relationship for weight and length/height among children aged $1-6$ years than those aged $<$ one year and $7-12$ years (fig 1 and 2).

\section{Number of subjects in BMI groups: BMI based on actual weight and length/height vs. BMI based on estimates of those values}

Z-scores were generated for both actual and estimated BMI derived by actual and estimated weigh and length/height. On the basis of the z scores, study subjects were then categorized into thin, overweight and obese. BMI Z-score cut-points of $<$ $-2.0,>+1.0$, and $>+2.0$ are recommended to define thinness, overweight and obese.15 Table III shows the prevalence of thinness, overweight and obesity using both the actual (observed) and the standardized BMI values. Table III shows that, altogether, one subjects were classified as thin on the basis of z scores of actual BMI, on the contrary none subject were identified as thin using $\mathrm{z}$ scores of estimated BMI. Two subjects were classified as overweight on the basis of $\mathrm{z}$ scores of actual BMI while none subject were identified as overweight using $\mathrm{z}$ scores of estimated BMI. Also, five subjects were adjudged obese using estimated BMI: three of these five subjects were identified as obese using actual BMI.

Table I - Demographic characteristics of study populations

\begin{tabular}{lll}
\hline Character & Number & Percentage (\%) \\
\hline Gender & & \\
Male & 45 & 50.0 \\
Female & 45 & 50.0 \\
Total & 90 & 100.0 \\
\hline Age Group & & \\
$<1$ year & 5 & 5.6 \\
$1-6$ years & 49 & 54.4 \\
7 - 12 years & 36 & 40.0 \\
\hline
\end{tabular}

Table II: Mean actual and estimated anthropometric measurements of study subjects

\begin{tabular}{|c|c|c|c|c|}
\hline \multicolumn{5}{|c|}{ Anthropometric Measures } \\
\hline & $\begin{array}{l}\text { Actual } \\
\text { Mean (SD) }\end{array}$ & $\begin{array}{l}\text { Estimate } \\
\text { Mean (SD) }\end{array}$ & t- value & p- value \\
\hline Weight & $17.9(7.3)$ & $20.8(10.1)$ & 0.885 & $0.029^{*}$ \\
\hline Height & $109.2(23.8)$ & $109.8(23.6)$ & 0.920 & 0.865 \\
\hline BMI & $14.7(3.2)$ & $15.9(1.8)$ & 0.118 & $0.002 *$ \\
\hline
\end{tabular}

Table III: Comparison of BMI based on actual weight and length/height vs. BMI based on estimates of those values

\begin{tabular}{llll}
\hline & Thinness & 0verweight & Obesity \\
Estimated BMI & 0 & 0 & 5 \\
Actual BMI & 1 & 2 & 3 \\
\hline
\end{tabular}




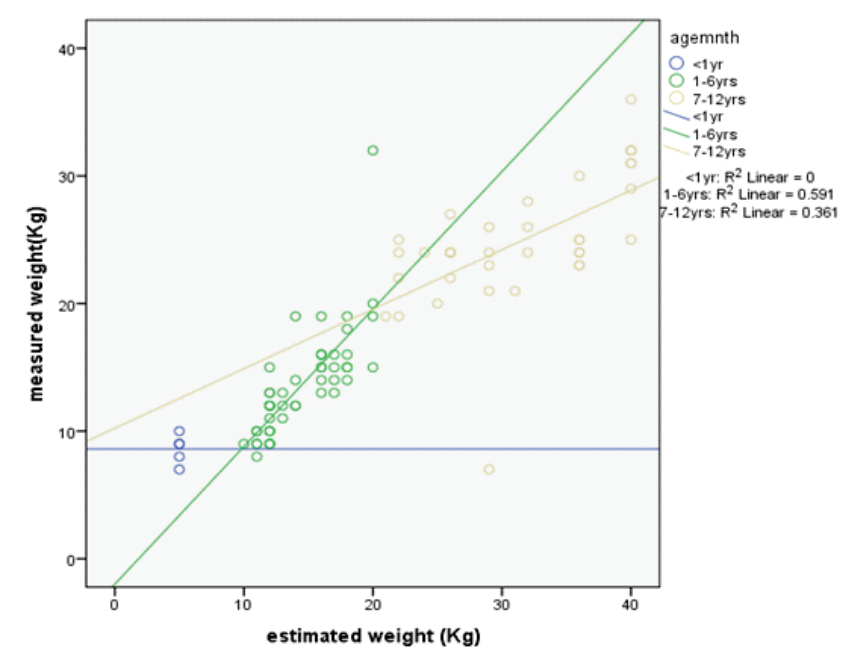

Fig 1: scatter plot of actual weight and estimated weight

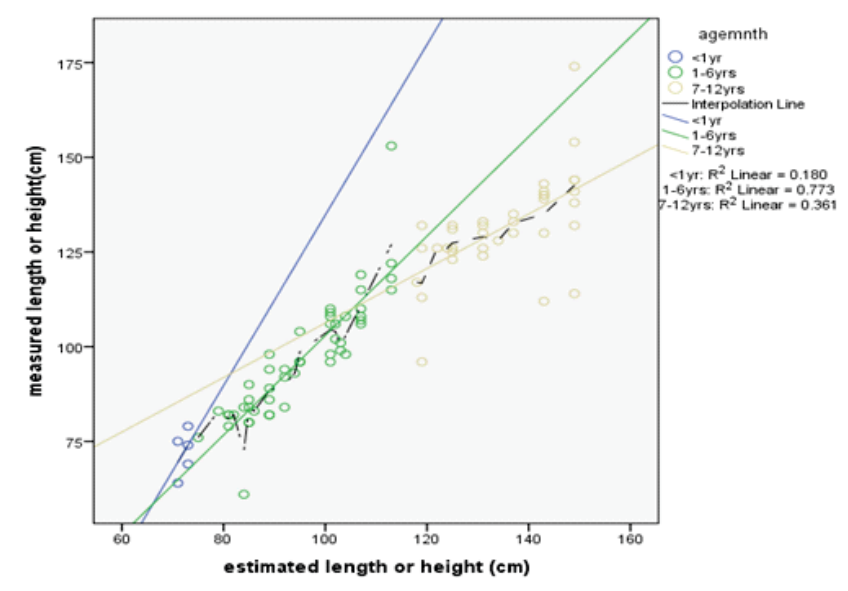

Fig 2: scatter plot of actual length/height and estimated length/height

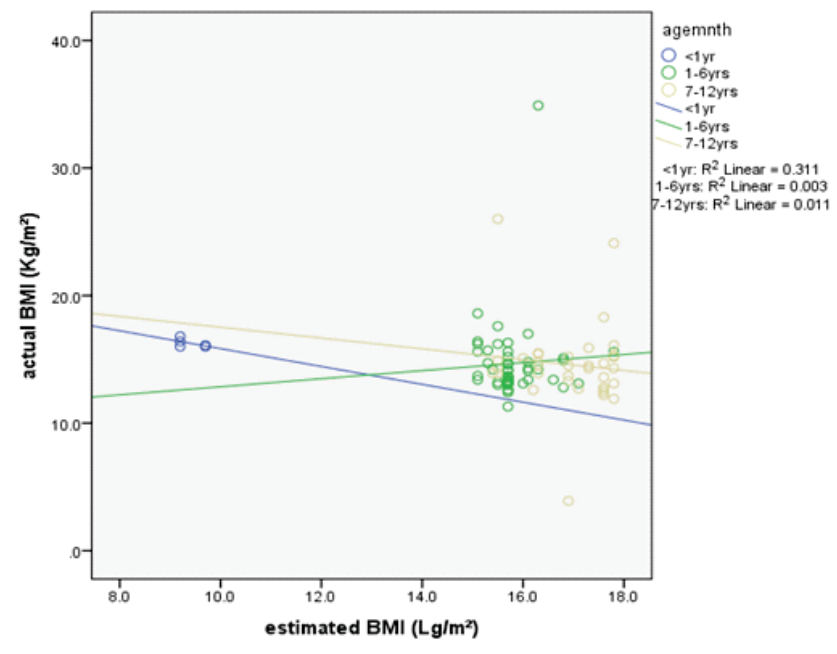

Fig 3: scatter plot of actual BMI and estimated BMI

\section{DISCUSSION}

The measurement of weight, height/length, and body mass index is an invaluable tool in paediatric settings. They are measurement required for the evaluation of growth, calculation of nutritional indices, prediction and standardization of physiological variables such as lung volumes, ${ }^{16}$ glomerular filtration rate, metabolic rate, and for the tailoring of drug dosage in patients. ${ }^{17}$ In the emergency situations, fast and accurate methods of weight and height estimation are needed for immediate therapeutic interventions in order to save lives of children with sickle cell anaemia in crisis. Many estimation methods currently exist for general paediatric usage but most may not be relevant in children with sickle cell anaemia resulting in the fact that the formula estimation of weight or height may be overestimating the actual value in many of these children. Present study is the first attempt to determine whether estimated weight and height among children with sickle cell anaemia agrees with measured weight and height.

The present study shows that estimates of weight, height/length and BMI among children with sickle cell anaemia done using standard formula by healthcare workers were generally adequate, although overestimation of weight and height were as large as $2.9 \mathrm{Kg}$ and $0.6 \mathrm{~cm}$ respectively. Length/height estimates were more accurate than weight estimates which was revealed by the relative closeness of the mean estimated height/length values to the mean measured height/length values. The over-estimation of weight and height using standard formula methods will result in significant over - dosing of some emergency drugs such as opoids for analgesia among children with sickle cell anaemia which will be more pronounced using estimated weight. The estimated mean weight value was significantly higher than the actual weight in the current study. This is most likely a consequence of effect of sickle cell anaemia on childhood growth. There was no consistent pattern observed between the estimated and actual weight. These observed differences may also be due to disparity in severity of illness among the study subjects which is incomparable. The reason why the estimated mean weight and not the mean height or both was significantly higher than the actual parameters was not apparent as both are linear growth parameters and which should be more affected by sickle cell disorder is difficult to predict.

In this present study the strongest positive correlations for 
weight and length/height among children aged $1-6$ years compared with aged below one year and $7-12$ years. The findings are not surprising because both the weight and length/height variables are linear measurements which increase physiologically in the same direction with age. Considering the fact that under-nutrition is prevalent in Nigeria especially among under -five children ${ }^{18,19}$ and sickle cell anaemia commonly affects linear growth, ${ }^{6-10}$ the formula over-estimating the weights and heights of the subjects was not an incidental findings. These formulae as applied in the current study were proposed many years ago. The growth pattern of children may have changed with poor nutrition as a result of worsening economic situation. Not surprisingly, we found a significantly higher estimated BMI compared with actual BMI. For the purpose of this study, actual BMI was calculated on the basis of actual height and weight, and estimated BMI was calculated on the basis of estimated height and weight values. With a higher estimated weight values than actual and comparable values for both actual and estimated values, if BMI is estimated in this case, estimation of BMI may lead to misleading results. In our study, patients with the lowest BMI were more likely to have an underestimated body weight, and patients with the highest BMI were more likely to have body weight overestimated.

In the current study the estimated BMI derived from estimated weight and height was observed not to identify the only one and two subjects with thinness and overweight respectively. On the contrary the estimated BMI were more likely to overestimate subjects with obesity. It is attractive to conclude that estimated BMI is not a good tool to identify nutritional abnormalities among children with sickle cell anaemia as they may fall into a wrong BMI category.

\section{CONCLUSION}

We conclude that estimation of length/height, weight, and BMI by healthcare workers is adequate in general. Height is generally better estimated than is weight. Overestimation of body fat content occurred particularly in the thinness and overweight subjects, whereas overestimation of body fat content occurred especially in subjects with a high BMI in obesity category. There is need for a multi-centre cohort study to test the various formulae in our children.

\section{Limitation}

The major limitation of the study is the small sample number which provided too small of affected patients with growth deficit by sickle cell anaemia to make conclusive remarks. There is a need for collaborative, multicentre study involving larger pool of children with varying severity of sickle cell anaemia to confirm whether the standard equations are equally useful among children with sickle cell anaemia. The present study is to be considered as a first step in assessing the reliability of the standard formula among children with sickle cell anaemia.

\section{Conflict of Interest}

None declared.

\section{REFERENCES}

1. Serjeant GR, Serjeant BE. Sickle cell disease. $3^{\text {rd }}$ ed. New York: Oxford University Press; 2001.

2. Adekile AD, Adeodu OO. Haemoglobinopathies. In: Azubuike JC, Nkanginieme KEO (editors). Textbook of Paediatrics and Child Health in a Tropical Region. 2nd ed. Owerri: African Educational Services; 2007; $373-90$.

3. Makani J, Konba AN, Cox SE, Oruo J, Mwamtemi $\mathrm{K}$, Kitundu J, et al. Malaria in patients with sickle cell anaemia: burden, risk factors, and outcome at the outpatient clinic and during hospitalization. Blood 2010; 115: 215 - 220.

4. Iwalokun BA, Iwalokun SO, Hodonu SO, Aina AO, Agomo PU. Serum levels of leptin in Nigerian patients with sickle cell anaemia. BMC Blood Disorders 2011; 11: 1 - 11

5. World Health Organization. Report by the Secretariat of the Fifty-ninth World Health Assembly A59/9 2006

6. Barden EM, Kawchak DA, Ohene-Frempong K, Stallings VA, Zemel BS. Body composition in children with sickle cell disease. Am J Clin Nutr 2002; 76: 218 - 25

7. Mukherjee MB, Gangakhedkar RR. Physical growth of children with sickle cell disease. Indian J Hum Genet 2004; 10: 70 - 2

8. Silva C. Growth Deficits in Children with Sickle Cell Disease. Arch Med Res 2003; 33: 308 - 12

9. Emodi KJ, Kaine WN. Weights, Heights, and Quetelet's indices of children with sickle cell anaemia (sicklers). Nig J Paediatr 1996; 23: 37 - 41.

10. Ogunrinde GO, Yakubu AM, Akinyanju OO. Anthropometric measures and zinc status of children with sickle cell anaemia in Zaria. Nig J Paediatr 2000; 27: 64 - 9 .

11. Awotua-Efebo O, Alikor EAO, Nkanginieme KEO. Malaria parasite density and splenic status by ultrasonography in stable sickle cell anaemia (HbSS) children. Nig J Med 2004; 13: 40 - 4. 
12. Henderson RA, Saavedra JM, Dover GJ. Prevalence of impaired growth in children with homozygous sickle cell anemia. Am J Med Sci 1994; 307: $405-$ 7.

13. Keane V. Assessment of growth. In Nelson textbook of paediatrics, $18^{\text {th }}$ edition

14. Akodu SO, Njokanma OF, Kehinde OA. Cormic index in Nigerian children with sickle cell anaemia. Anemia 2014

15. WHO and UNICEF. WHO child growth standards and the identification of severe acute malnutrition in infants and children A Joint Statement by the World Health Organization and the United Nations Children's Fund. Geneva: WHO and UNICEF 2009.

16. Golshan M, Crapo RO, Amra B, Jensen RI, Golshan $\mathrm{R}$. Arm span as an independent predictor of pulmonary function parameters: validation and reference values. Respirology 2007; 12: $361-6$

17. Zverev YP. Relationship between arm span and stature in Malawian adults. Annals of Human Biology 2003; 30: 739 - 43.

18. Cheymol G. Effects of obesity on pharmacokinetics: implications of drug therapy. Clinical pharmacokinetics 2000;39(2): 215-231.

19. Sebanjo IO, Olayiwola IO, Afolabi WA, Sebanjo OC. Maternal and child undernutrition in rural and urban communities of Lagos State, Nigeria: the relationship and risk factors. BMC Research Notes 2013, 6:286 